Recently it was described that some carbohydrates enhanced the vitamin $B_{12}$ absorption s. It is possible that the free sialic acids may be of importance for this trans. port.

1. Werner, I. and Blix, G. Bull, soc. chim. Belges 65 (1956) 202.

2. Mártensson, E., Raal, A. and Svennerholm, L. Acta Chem. Scand. 11 (1957) 1604.

3. Mårtensson, E., Raal, A. and Svennerholm, L. (In manuscript.)

4. Pettersson, S-O., Sivertsson, R., Sjögren, S. and Svennerholm, L. Biochim. et Biophys. Acta. (In press.)

5. Martinsson, A., Raal, A. and Svennerholm, L. Biochim. et Biophys. Acta 23 (1957) 652.

6. Klenk, E. and Uhlenbruck, G. Hoppe Seyler's Z. physiol. Chem. 307 (1957) 266.

7. Blix, G., Lindberg, E., Odin, L. and Werner, I. Acta Soc. Med. Upsaliensis 61 (1956) 1.

8. Greenberg, S. M., Herndon, J. F., Rice, E. G., Pamelec, E. T., Gulesich, J. J. and van Loon, E. J. Nature 180 (1957) 1401.

Received February 8, 1958.

\section{The Losses of Vitamin A during Chromatography}

GEORG LAMBERTSEN and OLAF R. BRAKKAN

\section{Governmental Vitamin Laboratory, Norwegian Fisheries Research Institute, Bergen, Norway}

$W_{s}^{\text {he }}$ hen the irrelevant absorption in the spectrophotometric determination of vitamin A exceeds certain limits, the geometric correction method according to Morton and Stubbs ${ }^{2}$ is unreliable, and purification of the vitamin A fraction by chromatography is recommended. Actually chromatography is included in the procedure described in official methods in some countries. The chromatography is most often carried out on alumina columns by some modification of the method described by Gridgeman, Gibson and Savage for the estimation of vitamin $A$ in whale liver oils. A certain activity of the alumina is needed to obtain a sufficient separation of the unsaponifiable substances, but unfortunately a higher activity also means a higher loss of vitamin $A$ in the procedure. In our experience the most potent oils give the highest losses, even up to $10 \%$ for some vitamin A concentrates. Such losses can be counteracted by deactivation of the alumina. Usually a standardized activity is obtained by uniform water addition. To avoid this difficulty the use of a softer adsorbent, e.g. calcium phosphate has been introduced ${ }^{3}$. It is, however, of importance to obtain standardized columns in different laboratories, and alumina is the adsorbent preferred as it can be obtained readily in uniform quality everywhere as "Aluminium Oxide Standardized for Adsorption analysis according to Brockman". As mentioned above, a softening of the alumina is necessary to make it useful. Such deactivation will, however, result in a reduced separation of the components in the unsaponifiable matter. A limit thus has to be found where conditions are optimal all factors considered. This means that a certain loss is unavoidable, and must be controlled and taken into consideration by using a standard.

We have been trying to find substances which, added to the vitamin A fraction, would reduce the losses during the chromatography. Gridgeman et al. ${ }^{2 a}$ found it advisable to add cholesterol to make up the weight of the unsaponifiable matter if this amounted to less than $0.35 \mathrm{~g}$. We found cholesterol to be of no effect in preventing the loss of vitamin $A$. Neither did several other types of substances, e.g. fatty alcohols or glyceryl ethers, have any such effect. The unsaponifiable matter of ground nut oil, however, gave a striking reduction in the loss. In one experiment the unsaponifiable matter of $0.5 \mathrm{~g}$ of ground nut oil gave a recovery of $98 \%$ of a total of 2000 I.U. vitamin A compared to $90 \%$ without addition. The effect was found in the fraction of the unsaponifiable matter passing the alumina column with a speed similar to vitamin A. Analysis on paraffinated paper as described by Green, Marcinkiewicz and Watt " showed that the effective fraction contained $\gamma$-tocopherol. Pure $\gamma$-tocopherol (Eastman-Kodak) was then tried, and the effect was obtained with as little as $200 \mu \mathrm{g}$ added per 1000 I.U. vitamin A put through the column. $a$-Tocopherol had no effect, but as other slow moving tocopherols might be effective, the unsaponifiable matter of other vegetable oils were tried. Soy bean oil with its high concentration of $\gamma$ - and $\delta$-tocopherols $(1.000 \mu \mathrm{g}$ per g compared with $200 \mu \mathrm{g}$ per $\mathrm{g}$ in ground nut oil) protected effectively against losses. Alumina columns of the 
type used for vitamin A chromatography will not separate dimethyltocols from momomethyltocols, and the effect of the unsaponifiable matter may be a joint effect of $\gamma$-and $\delta$-tocopherols. This is indicated by the fact that soy bean oil containing 5 times as much totally of these tocopherols than ground nut oil, is effective in one-fifth of the concentration.

The effect of these tocopherols is not one of simple displacement, as $\gamma$-tocopherol failed to elute further vitamin $\mathrm{A}$ from a column where vitamin $A$ had passed through without protection. It may be a pure antioxidant effect protecting against oxidative substances in solvents and adsorbent. A more likely theory is that the tocopherols take the place of vitamin $A$ in irreversible adsorption on the alumina. This is indicated by the recovery of anhydrovitamin A by ethanol elution of a column where vitamin A had passed with a loss.

The last 1-2\% loss of vitamin A during chromatography may arise from the diffusion of the vitamin A-band on the column. It was possible to prove the presence of vitamin $A$ by concentration of the fractions leaving the column before and after the vitamin A-fraction. Carr-Price spot tests or fluorescence test with U.V.-light had given no positive reaction of vitamin $A$ in these fractions.

Tocopherol-fractions useful for the purpose of protection against losses of vitamin A in chromatography can be produced easily from a proper vegetable oil, and be stored in hexane in the freezer for a couple of months. It is recommended to add a suitable aliquot of such a solution to the vitamin A fraction before chromatography of medium and high potent oils.

1. Morton, R. A. and Stubbs, A. L. Analyst 71 (1946) 348.

2. Gridgeman, N. T., Gibson, G. P. and Savage, J. P. Analyst 73 (1948) 662. 2a. See discussion.

3. Hjarde, W. Acta Chem. Scand. 4 (1950) 628.

4. Green, J., Marcinkiewicz, S. and Watt, P. R. J. Sci. Food Agric. 6 (1955) 274.

Received February 10, 1958.

\section{The Isolation of O-Phospho- ethanolamine from the Rest Protein Fraction of Escherichia coli $\mathrm{B}$}

C A R L-HEN R I C D E ER D I R and GUN NAR A GREN

Institute of Medical Chemistry, University of Uppsala, Sweden

Tn earlier communications ${ }^{1,2}$ it has been shown that acid hydrolysates of the Schneider rest protein fractions from mammalian organs contain O-phosphoserine and O-phosphothreonine. Phosphoserine has also been isolated from the corresponding protein fraction of yeast ${ }^{3}$ but in other microorganisms phosphorylated hydroxyamino acids of different composition seem to dominate in the acid hydrolysates 4,5 .

It has now been possible to isolate $O$ phosphoethanolamine in crystalline form from the acid hydrolysate of the rest protein fraction of $E$. coli. Previously published methods for isolation have been followed. The bacteria were harvested at the end of the lag phase. They had been cultivated for about $2 \mathrm{~h}$ on a medium contain. ing $1 \mathrm{mC}$ radioactive phosphate per liter ${ }^{\circ}$ to facilitate the identification of phosphorus compounds. Fig. 1 shows the elution curve of the hydrolysed cell walls in the first step of purification through a Dowex-50 column. Of the three main peaks (I, III, V) No. I consists of inorganic phosphate, No. III is a mixture of at least three ninhydrin positive compounds which are not identical with phosphoserine or phosphothreonine. No. $\mathrm{V}$ is practically pure phosphoethanolamine. Peak No. II is probably a nucleotide since it gives UV. absorption at $260 \mathrm{~m} \mu$ and no ninhydrin reaction. A hydrolysate of peak No. IV shows on a paper chromatogram mainly ethanolamine and a few other weaker nin. hydrin spots. Sufficient amounts of material for the identification of peak No. V was obtained by mixing radioactive bacteria with large amounts of unlabelled cells. For large scale cultivation the microorganisms were incubated in a 1000 liter tank on the same medium for about $20 \mathrm{~h}$. The usual yield of fresh bacteria from a single cultivation was about $2.5 \mathrm{~kg}$. Material from two cultivations was used in this study.

Acta Chem. Scand. 12 (1958) No. 2 